\title{
Symptoms of fatigue and coping strategies in maritime pilotage
}

\author{
Timothy P. Chambers ${ }^{1}$, Luana C. Main ${ }^{2}$ \\ ${ }^{1}$ School of Psychological Sciences, Australian Collage of Applied Psychology, Melbourne, Australia \\ ${ }^{2}$ Centre for Physical Activity and Nutrition Research, Deakin University, Burwood, Australia
}

\begin{abstract}
Background: Little is known regarding the symptoms of fatigue that maritime pilots experience during shift work. Moreover, the strategies these individuals use to cope with the onset of fatigue are also unknown. The current study explored the symptoms of fatigue and coping strategies experienced by maritime pilots when on-shift. Material and methods: Fifty maritime pilots were recruited via an advertisement in the national association's quarterly newsletter $\left(M_{\text {age }}=51.42 ; S D=9.81\right.$ ). Participants responded to a modified version of the questionnaire used with aviation pilots that assessed overall fatigue, and the symptoms pilots associated with fatigue on duty. Methods pilots used to cope with fatigue before shift and when on the bridge were also assessed. Results: There were significant effects for pilot vitality on 4 categories of fatigue: cognitive dysfunction; emotional disturbance; mean physical effects; and sleepiness. There were no significant effects for vitality on any of the self-reported coping strategy factors.

Conclusions: The findings indicated that maritime pilots experience a variety of physical, behavioural, and cognitive fatigue symptoms when on shift. Some of these symptoms are similar to those reported by aviation pilots. However, unlike aviation pilots, maritime pilots reported utilising self-sufficient coping strategies to deal with the experience of fatigue.
\end{abstract}

(Int Marit Health 2015; 66, 1: 43-48)

Key words: shift-work, vitality, mental health, pilots

\section{INTRODUCTION}

Individuals working in high stress environments for long durations are known to experience conditions that may exacerbate fatigue and affect performance [1], with reports acknowledging that one of the most dangerous and demanding work environments is the sea [2]. Investigations of maritime industry related accidents that resulted in injury and/or death have indicated that the incidence of such accidents peaks in early morning and rises again during the evening $[3,4]$. Between $50 \%$ and $90 \%$ of these accidents are attributed to human error [5]. Preliminary maritime research suggests that sleepiness, fatigue, and disruptions to circadian rhythm may have contributed to the significant accidents that resulted in maritime casualties [6]. In a review of various human factors that contribute to safety in the maritime industry it was noted that extended hours on-duty, and the total number of hours worked in 3 consecutive days, contributed to accidents that were later attributed to worker fatigue [1]. Compared to other transportation industries, fatigue is disproportionally under-researched in the maritime domain [7]. Of the available maritime literature on fatigue, the vast majority focuses on seafarers (e.g., captains, crew members $[2,7]$ ) with very little attention paid to maritime pilots.

Maritime pilotage is a demanding occupation where pilots are required to perform complex procedures in sometimes unfamiliar working environments [8]. Specifically, maritime pilots are responsible for ensuring the safe passage of vessels into, and out of port, which is deemed a high-risk exercise [9]. These navigational tasks result in long periods of intense work that can affect routine sleep schedules [5]. As the execution of these challenging procedures occurs 
during lengthy shifts, due to commercial pressures [7], fatigue is thought to play a considerable role in pilotage performance. In particular, fatigue is thought to result in cognitive performance decrements and increased mood disturbances [10]. The potential for experiencing fatigue on shift is considerable given the demands of this occupational environment [4], including short turn-around times, increased automatisation, and interrupted working routines [2]. At present, there is a shortage of maritime pilot-specific research that reveals the impact of fatigue and coping on performance. Given that human error has been identified as a primary cause of most transportation related accidents [11], and that the number and size of ships in commercial waterways is increasing [9] it is critical that maritime pilotage research examines factors related to human performance.

To explain mariner behaviour and the consequences of fatigue on work performance, previous investigations have often turned to other transportation industries [4]. Specifically, maritime pilotage researchers often turn to the aviation industry for guidance regarding what factors may influence pilot performance [4] due to perceived similarities in the respective roles (e.g., highly specialised knowledge). Aviation researchers have previously demonstrated that there are many factors that contribute towards pilot fatigue, including the duration (e.g., 2-12 h), and the irregular hours of shift work (e.g., 2 am to 6 am [12, 13]). Moreover, aviation pilots also experience cognitive dysfunction, emotional disturbance, boredom, and altered sleeping arrangements when flying a long-haul flight [14]. To cope with such symptoms, aviation research has revealed that active coping, mental withdrawal, and co-worker communication were key strategies employed by pilots [14]. Collectively, this research highlights the various factors that impact on fatigue and the various strategies employed to overcome fatigue by individuals in a highly stressful and demanding occupation. Whether maritime pilots experience similar performance decrements as a consequence of task workload and duration on performance remains to be investigated.

To date, much of the available maritime literature documents the fatigue and sleepiness experienced by permanent crew members [5], not maritime pilots. Moreover, the strategies maritime pilots employ to cope with the onset of fatigue are also unknown. Therefore, the aim of the current study was to firstly compare self-reported symptoms of fatigue in maritime pilots with aviation pilots as reported by Petrie and Dawson [14]; and secondly to identify whether the coping strategies they employ to manage fatigue were consistent with aviation pilots, particularly when higher levels of fatigue were reported. It was anticipated that some differences in fatigue symptoms and coping strategies would be evident between maritime and aviation pilots due to different situational demands.

\section{MATERIALS AND METHODS}

\section{PARTICIPANTS}

Fifty maritime pilots (49 male; $\mathrm{M}_{\text {age }}=51.42 ; \mathrm{SD}=9.81$ ) currently employed across ports in Australia and New Zealand participated in the research study. The mean years of pilotage experience was 14.26 years $(S D=9.62)$. Approval to conduct the research was obtained from the Human Research Ethics Committee, and the research was conducted in accordance with the Helsinki Declaration (revised 2013).

\section{MATERIALS}

Vitality Scale. The 9 item Vitality Scale from the short form Health Survey [15] was used to measure overall pilot fatigue. Responses were recorded on a 6-point Likert scale ranging from 1 (none of the time) to 6 (all of the time). High levels of vitality scale validity and reliability were previously reported in general and medical contexts [15].

Symptoms of fatigue. Using the 10-item symptoms of fatigue checklist reported by Petrie and Dawson [14], participants rated their perceived level of fatigue on a 5-point Likert scale from 1 (never) to 5 (always). According to Petrie and Dawson [14] these items collapse into 5 clusters of fatigue symptoms including; cognitive dysfunction, emotional disturbance, physical effects, boredom, and sleepiness. Examples items include 'having difficulty planning' (cognitive dysfunction item) and 'sore eyes' (physical effect item).

Coping strategies. The 10-item coping strategies checklist described by Petrie and Dawson [14] was used to measure work-related coping. Participants recorded coping on a 5-point Likert scale from 1 (never) to 5 (always). The 10 items again collapse into 5 clusters of coping strategies and include: energy planning, active coping, mental withdraw, crew communication, coffee drinking. Example items include 'take things one step at a time' (energy planning item) and 'tell the other crew how I feel' (crew communication item).

\section{PROCEDURE}

Following ethics approval to conduct the research, a project advertisement was placed in the national maritime pilotage association's quarterly newsletter that included a link to the online survey. Snowball recruitment techniques were also employed using the author's contacts in the industry. An email outlining the purpose of the research was sent to known maritime pilots in Australia from these contacts with no obligation or incentive to volunteer. Participants completed the following questionnaires in order of presentation: Vitality Scale, symptoms of fatigue, coping strategies, and participant demographics. Completion of the survey took approximately $15 \mathrm{~min}$. 


\section{DATA ANALYSIS}

All statistical analyses were completed using SPSS V.21 (IBM, New York). Prior to the analyses, data were screened for homogeneity and violation of assumptions of normality. Data were deemed to be homogeneous, with no violations evident. For exploratory purposes, fatigue symptoms (Table 1) and cop- ing strategies (Table 2) are reported for each vitality quartile (i.e. mean and standard deviation [SD]). Using the factor structures presented by Petrie and Dawson (14), one-way ANOVA's were conducted to examine the impact of fatigue (i.e. Vitality) on the reported symptoms of fatigue and coping strategies employed. The accepted significance level was $p<0.05$.

Table 1. Comparison of fatigue symptoms across vitality quartiles

\begin{tabular}{|c|c|c|c|c|c|c|c|c|c|c|c|c|c|}
\hline \multirow[b]{3}{*}{ Symptoms of fatigue } & \multicolumn{3}{|c|}{ High fatigue } & \multirow{2}{*}{\multicolumn{3}{|c|}{$\begin{array}{l}\text { Moderate fatigue } \\
\text { Vitality score: } 37-40\end{array}$}} & \multirow{2}{*}{\multicolumn{3}{|c|}{$\begin{array}{l}\text { Mild fatigue } \\
\text { Vitality score: } 41-44\end{array}$}} & \multirow{2}{*}{\multicolumn{3}{|c|}{$\begin{array}{l}\text { Low fatigue } \\
\text { Vitality score: } 45-50\end{array}$}} & \multirow{3}{*}{$\begin{array}{l}\text { Petrie } \\
\text { and } \\
\text { Dawson } \\
\text { ranking }\end{array}$} \\
\hline & \multicolumn{3}{|c|}{ Vitality score: $21-36$} & & & & & & & & & & \\
\hline & Rank & Mean & SD & Rank & Mean & SD & Rank & Mean & SD & Rank & Mean & SD & \\
\hline 1. Felt sleepy & 1 & 3.33 & 0.49 & $=2$ & 2.85 & 0.38 & 1 & 3.00 & 0.00 & 1 & 2.58 & 0.51 & 1 \\
\hline 2. Felt low in energy & 2 & 3.25 & 0.62 & $=2$ & 2.85 & 0.55 & 2 & 2.92 & 0.28 & $=3$ & 2.33 & 0.65 & 2 \\
\hline 3. Miss things & $=3$ & 2.75 & 0.45 & 6 & 2.46 & 0.66 & 3 & 2.77 & 0.44 & 2 & 2.42 & 0.51 & 10 \\
\hline $\begin{array}{l}\text { 4. Become grouchy } \\
\text { or irritable }\end{array}$ & $=3$ & 2.75 & 0.45 & 1 & 2.92 & 0.28 & 5 & 2.62 & 0.51 & 8 & 1.91 & 0.67 & 5 \\
\hline 5. Feel mentally slow & 7 & 2.67 & 0.49 & 6 & 2.46 & 0.52 & 4 & 2.69 & 0.48 & $=3$ & 2.33 & 0.49 & 3 \\
\hline 6. Lose concentration & $=3$ & 2.75 & 0.45 & 8 & 2.38 & 0.50 & 8 & 2.54 & 0.52 & 5 & 2.17 & 0.39 & 4 \\
\hline 7. Become forgetful & 8 & 2.58 & 0.67 & 4 & 2.54 & 0.66 & 9 & 2.38 & 0.51 & 5 & 2.17 & 0.58 & 7 \\
\hline $\begin{array}{l}\text { 8. Become easily } \\
\text { distracted }\end{array}$ & 9 & 2.42 & 0.67 & 9 & 2.23 & 0.60 & 5 & 2.62 & 0.51 & 7 & 2.00 & 0.43 & 9 \\
\hline 9. Sore eyes & $=3$ & 2.75 & 0.87 & 4 & 2.54 & 0.78 & 10 & 2.15 & 0.55 & 9 & 1.75 & 0.87 & 6 \\
\hline 10. Have difficulty planning & 10 & 2.17 & 0.58 & 10 & 1.85 & 0.69 & 5 & 2.62 & 0.65 & 10 & 1.67 & 0.65 & 8 \\
\hline
\end{tabular}

Note: Symptoms of fatigue presented in rank order for the whole cohort $(n=50)$.

Table 2. Comparison of coping strategies across vitality quartiles

\begin{tabular}{|c|c|c|c|c|c|c|c|c|c|c|c|c|c|}
\hline \multirow[b]{3}{*}{ Coping strategies } & \multirow{2}{*}{\multicolumn{3}{|c|}{$\begin{array}{l}\text { High fatigue } \\
\text { Vitality score: 21-36 }\end{array}$}} & \multirow{2}{*}{\multicolumn{3}{|c|}{$\begin{array}{l}\text { Moderate fatigue } \\
\text { Vitality score: } 37-40\end{array}$}} & \multirow{2}{*}{\multicolumn{3}{|c|}{$\begin{array}{l}\text { Mild fatigue } \\
\text { Vitality score: } 41-44\end{array}$}} & \multirow{2}{*}{\multicolumn{3}{|c|}{$\begin{array}{l}\text { Low fatigue } \\
\text { Vitality score: } 45-50\end{array}$}} & \multirow{3}{*}{$\begin{array}{l}\text { Petrie } \\
\text { and } \\
\text { Dawson } \\
\text { ranking }\end{array}$} \\
\hline & & & & & & & & & & & & & \\
\hline & Rank & Mean & SD & Rank & Mean & SD & Rank & Mean & SD & Rank & Mean & SD & \\
\hline $\begin{array}{l}\text { 1. Try and be as orga- } \\
\text { nised as possible }\end{array}$ & 1 & 4.33 & 0.78 & 1 & 4.38 & 0.65 & $=1$ & 4.15 & 0.69 & 1 & 4.58 & 0.51 & 5 \\
\hline $\begin{array}{l}\text { 2. Get up and walk } \\
\text { around }\end{array}$ & $=3$ & 3.92 & 0.67 & 2 & 4.23 & 0.73 & $=1$ & 4.15 & 0.55 & 2 & 4.33 & 0.78 & 4 \\
\hline $\begin{array}{l}\text { 3. Keep busy and } \\
\text { active }\end{array}$ & 5 & 3.83 & 1.03 & 3 & 3.77 & 0.73 & 3 & 4.08 & 0.64 & 3 & 4.00 & 0.60 & 6 \\
\hline $\begin{array}{l}\text { 4. Keep my mind } \\
\text { busy and active }\end{array}$ & $=3$ & 3.92 & 0.67 & 4 & 3.62 & 0.77 & 4 & 3.85 & 0.69 & $=4$ & 3.83 & 0.72 & 7 \\
\hline $\begin{array}{l}\text { 5. Make an extra } \\
\text { effort to fight } \\
\text { fatigue }\end{array}$ & 2 & 4.08 & 0.90 & 6 & 3.31 & 0.63 & 5 & 3.54 & 0.78 & $=4$ & 3.83 & 0.94 & 8 \\
\hline 6. Have a cold drink & 7 & 3.33 & 0.89 & 6 & 3.31 & 0.75 & 7 & 3.23 & 0.83 & $=4$ & 3.83 & 0.83 & 3 \\
\hline $\begin{array}{l}\text { 7. Take things one } \\
\text { step at a time }\end{array}$ & 6 & 3.50 & 0.80 & 8 & 3.08 & 0.76 & 7 & 3.23 & 0.60 & $=4$ & 3.83 & 0.72 & 1 \\
\hline $\begin{array}{l}\text { 8. Keep up a conver- } \\
\text { sation with other } \\
\text { crew }\end{array}$ & 8 & 3.08 & 0.79 & 5 & 3.38 & 0.77 & 6 & 3.46 & 0.88 & 8 & 3.50 & 0.80 & 2 \\
\hline 9. Eat more & 9 & 2.75 & 0.75 & 9 & 3.00 & 1.00 & 9 & 2.77 & 0.83 & 9 & 2.58 & 1.24 & 9 \\
\hline $\begin{array}{l}\text { 10. Tell other crew } \\
\text { how I feel }\end{array}$ & 10 & 1.83 & 0.72 & 10 & 2.31 & 1.03 & 10 & 1.69 & 0.75 & 10 & 2.25 & 0.87 & 10 \\
\hline
\end{tabular}




\section{RESULTS}

Descriptive statistics were calculated for all symptoms of fatigue, and coping strategies; with rank order of fatigue symptoms (Table 1) and coping strategies (Table 2) presented for the whole cohort $(n=50)$. For comparison, fatigue rankings by aviation pilots from Petrie and Dawson [14] are also included in Table 1. Table 2 depicts the rank order of coping strategies employed by pilots when on-shift and again includes aviation pilot rank order data from Petrie and Dawson [14].

There was a significant effect for vitality on Petrie and Dawson's [14] cognitive dysfunction factors of losing concentration $\left(\mathrm{F}_{3,49}=3.29, \mathrm{p}=0.029, \eta^{2}=0.18,95 \% \mathrm{Cl}\right.$ $2.32-2.60)$, and having difficulty planning $\left(\mathrm{F}_{3,49}=5.28\right.$, $\left.p=0.003, \eta^{2}=0.26,95 \% \mathrm{Cl} 1.87-2.29\right)$; and approaching significance, becoming easily distracted $\left(\mathrm{F}_{3,49}=2.77\right.$, $\left.p=0.052, \eta^{2}=0.15,95 \% \mathrm{Cl} 2.45-2.75\right)$. In terms of emotional disturbance [14], there was a significant effect for vitality on becoming grouchy or irritable $\left(\mathrm{F}_{3,49}=9.82\right.$, $\left.p=0.000, \eta^{2}=0.39,95 \% \mathrm{Cl} 2.39-2.73\right)$. For physical signs and symptoms [14], there was a significant effect for vitality on feeling low in energy $\left(F_{3,49}=5.88, p=0.002, \eta^{2}=0.28\right.$, $95 \% \mathrm{Cl} 2.66-3.02)$, feeling sleepy $\left(\mathrm{F}_{3,49}=7.47, \mathrm{p}=0.000\right.$, $\left.\eta^{2}=0.33,95 \% \mathrm{Cl} 2.81-3.07\right)$, and having sore eyes $\left(F_{3,49}=3.96, p=0.014, \eta^{2}=0.21,95 \% \mathrm{Cl} 2.06-2.54\right)$. However there were no significant effects on any of the self-reported coping strategy factors.

\section{DISCUSSION}

Little is known regarding the symptoms of fatigue that maritime pilots experience during shift work. Moreover, the strategies that these individuals use to cope with fatigue are also unknown. Previous investigations have likened maritime pilotage to aviation pilotage [4], yet no empirical research has directly compared pilotage across the two industries. While the maritime and aviation industries are very different domains, due to the perceived similarities in the respective roles, the aim of the current study was to compare self-reported symptoms of fatigue in maritime pilots when on shift against those reported by aviation pilots [14]. Results from the present study suggest that maritime and aviation pilots reported experiencing similar symptoms of fatigue. A second aim of the current study was to identify whether the coping strategies employed by maritime pilots to manage fatigue were consistent with those adopted by aviation pilots, particularly when higher levels of fatigue were reported. The findings indicated that the coping strategies employed by maritime pilots differed considerably to those utilised by aviation pilots.

Consistent with Petrie and Dawson [14], findings from the present study indicate that regardless of the amount of vitality experienced, symptoms of sleepiness and low energy levels were consistently the highest ranked fatigue symptoms by maritime pilots. As fatigue levels increased, maritime pilots were more likely report a loss of concentration, experience sore eyes, and become more grouchy or irritable. Although both maritime and aviation pilots report experiencing a range of related symptoms that affect physical and cognitive functioning, maritime pilots reported greater disruption to cognitive functioning. Specifically, maritime pilots reported missing things as a consistent symptom of fatigue, while in contrast, missing things was ranked 10 by aviation pilots [14]. This disparity may be reflective of a key difference in operational procedures between the two industries. Specifically, the aviation industry requires pilots to adhere to detailed checklists in-flight [16, 17], whereas the regulated use of checklists does not exist in the maritime industry. Overall, these results suggest that as fatigue increased, there was an observed increase in the reported physical, cognitive, and emotional effects of fatigue for maritime pilots.

Two plausible explanations for the differences between these professions are shift duration, and on-shift activity. First, maritime pilots have been known to complete shifts that can exceed $24 \mathrm{~h}$ duration $[18,19]$, which can result in a reduced amount of sleep. Research has indicated that a reduction in sleep quantity can result in increased behavioural and mood disturbance across various operational contexts [20]. The longer shifts performed by maritime pilots may explain why these pilots reported experiencing cognitive disruptions more frequently. This explanation is also consistent with broader maritime research, as previous investigations have demonstrated that a number of maritime-specific factors contribute to worker fatigue and decreases in cognitive and psychomotor performance (e.g., constant motion, interrupted sleep, excessive workload [21]).

Second, as the maritime industry moves to a greater reliance on automated systems [22], mariners are reporting increased fatigue due to the increased attentional demands of monitoring various electronic systems, for extended periods of time [1, 2]. For example, continuously monitoring dynamic navigational displays (e.g., electronic chart and display information system, RADAR) can reportedly result in the experience of excessive fatigue [23]. While navigational demands are becoming increasingly more complex with the advent of electronic navigational instrumentation [24], evidence indicates that attention and vigilance on psychomotor tasks decreases with the presence of fatigue during night shift [25]. Combined, these explanations are consistent with other maritime pilotage investigations that revealed work-related stress (e.g., shift-work) were a primary cause of health problems, including early fatigue and insomnia [9]. Therefore, it seems plausible that long shifts and the increased reliance on automated systems to improve efficiency may exacerbate worker fatigue and affect task performance. 
An examination of the coping results from the present study revealed that maritime pilots consistently reported that keeping as organised as possible, and walking around were preferred coping strategies, regardless of vitality scores. As vitality scores decreased, maritime pilots reported that making an extra effort to fight fatigue, and keeping their minds busy and active were also important coping strategies. While results revealed no difference in coping strategies across reported vitality quartiles, these findings suggest a preference for behavioural coping strategies when vitality is high, and an increased preference for cognitive strategies when vitality decreases. When comparing the coping strategies adopted by maritime pilots with aviation pilots [14], a number of subtle differences in preferred coping strategies emerged. For example, maritime pilots reported the need to be organised and make an effort to fight fatigue, which were the $5^{\text {th }}$ and $8^{\text {th }}$ ranked strategies utilised by aviation pilots [14]. It may be the case that maritime pilots perceive a need to employ physical and cognitive strategies to manage the experience of fatigue.

The differences in preferred coping strategies point to some fundamental differences in the roles and responsibilities of each occupation. First, compared to commercial aviation pilots, typically only 1 maritime pilot is responsible for negotiating the passage plan with the ship captain prior to departure, and navigating the vessel [9]. The maritime pilot is solely responsible for ensuring that he/she is familiar with any relevant meteorological data, specific vessel details, expected traffic through the passageway and harbour during a manoeuvre, or any other job-relevant information. It is perhaps of little surprise then that maritime pilots ensure that they are organised prior to commencing a job, and feel the need to fight fatigue if they are the individual solely responsible for ensuring the safe passage of the vessel.

Second, the 2 industries differ in the acceptance of compulsory personnel resource management training. Within the aviation industry, crew resource management (CRM) training specifically targets the improvement of teamwork, attitudes, and skills of aviation crews, including pilots [26]. Extensive research on crew effectiveness suggests that the introduction of CRM in commercial aviation resulted in a decrease in human-error related accidents $[27,28]$. Following the introduction of CRM, aviation pilots typically experience improved problem solving, decision making, and situational awareness. Similar training programs are evident within the maritime industry (e.g., Bridge Resource Management), yet they are not formally recognised and mandated as a requirement to perform maritime pilotage by the industry. Hence, the differences between maritime aviation pilots could be the consequence of resource management training.

\section{CONCLUSIONS}

Fatigue is known to be a subjective experience that can result in diminished physical and mental performance which has implications for people's ability to undertake tasks in a safe manner [29]. Anecdotally, maritime researchers and pilotage organisations often turn to the aviation industry for guidance regarding what factors may influence pilot performance [4] due to perceived similarities in the respective roles (e.g., highly specialised knowledge). The present study investigated the symptoms of fatigue and subsequent coping strategies employed by maritime pilots. Results indicated that maritime pilots experience a variety of physical, behavioural, and cognitive fatigue symptoms, with some similarities to those reported by aviation pilots. Contrary to aviation pilots, the maritime pilots reported utilising self-sufficient coping strategies to deal with the experience of fatigue. These findings provide a preliminary insight into the challenges associated with maritime pilotage and provide a platform for future research to investigate the cognitive and behavioural impact of fatigue on maritime pilotage. Context specific research is recommended prior to the adoption of any existing fatigue or bridge resource management strategies to improve performance in maritime pilotage as these industries are very different domains.

\section{KEY POINTS}

- Maritime pilots experience a variety of physical, behavioural, and cognitive symptoms of fatigue during shift work, some of which were similar to those reported by aviation pilots.

- Maritime pilots reported utilising self-sufficient coping strategies to deal with the experience of fatigue when on-shift, which varied compared to those employed by aviation pilots.

- The differences reported between the maritime and aviation industries point to the need for further context specific research prior to the implementation of non-specialised resource management programs in the maritime domain.

\section{ACKNOWLEDGEMENTS}

The authors wish to acknowledge Captain R. Main for his assistance with the study.

\section{AUTHOR CONTRIBUTIONS}

Both authors contributed equally to all aspects of the study design, data analysis, and manuscript preparation.

\section{DISCLAIMER}

It should be noted that the views of the authors expressed in the submitted article are their own and not an official position of either institution or funder. 


\section{REFERENCES}

1. Hetherington C, Flin R, Mearns K. Safety in shipping: The human element. J Safety Research 2006; 37: 401-411. doi:10.1016/ j.jsr.2006.04.007

2. Iversen RTB. The mental health of seafarers. Int Maritime Health 2012; 63: 78-89.

3. Sanquist TF, Raby M, Forsythe A, Carvalhais AB. Work hours, sleep patterns and fatigue among merchant marine personnel. J Sleep Research 1996; 6: 245-251.

4. Smith A, Allen P, Wadsworth E. Seafarers' fatigue: the Cardiff Research Programme. MCA, Southampton 2006.

5. Raby M, Lee JD. Fatigue and workload in the maritime industry. In: Hancock PA, Desmond PA eds. Stress, workload, and fatigue: human factors in transportation. Lawrence Erlbaum Associates, London 2001: 566-578.

6. Lauber JK, Kayten PJ. Sleepiness, circadian dysrhythmia, and fatigue in transportation accidents. Sleep 1988; 11: 503-512.

7. Allen $P$, Wadsworth $E$, Smith A. Seafarers' fatigue: a review of the recent literature. Int Marit Health 2008; 59: 81-92.

8. Darbra RM, Crawford JFE, Haley CW, Morrison RJ. Safety culture and hazard risk perception of Australian and New Zealand maritime pilots. Marine Policy. 2007; 31: 736-745. doi:10.1016/ /j.marpol.2007.02.004.

9. Andresen M, Domsch ME, Cascorbi AH. Working unusual hours and its relationship to job satisfaction: A study of European maritime pilots. J Labour Research 2007; 28: 714-734. doi: 10.1007/ s12122-007-9010-5.

10. Raby M, McCallum MC. Procedures for investigating and reporting fatigue contributions to marine casualties. Proceedings of the $41^{\text {st }}$ Human Factors and Ergonomics Society Annual Meeting; 1997 September 22-26; Albuquerque, US.

11. Harrald JR, Mazzuchi TA, Spahn J, Van Dorp R, Merrick J, Shrestha $\mathrm{S}$. Using system simulation to model the impact of human error in a maritime system. Safety Science 1998; 30: 235-247.

12. Powell D, Spencer MB, Holland D, Petrie KJ. Fatigue in two-pilot operations: Implications for flight and duty time limitations. Avi Space Environ Med 2008;79: 1047-1050.

13. Hartzler BM. Fatigue on the flight deck: the consequences of sleep loss and the benefits of napping. Accident Analysis Prevention 2014; 62: 309-318. doi.org/10.1016/j.aap.2013.10.010

14. Petrie KJ, Dawson AG. Symptoms of fatigue and coping strategies of aviation pilots. Int J Avi Psych 1997; 7: 253-258.

15. Ware JE. SF-36 Health Survey Manual and interpretation guide. The Health Institute, Boston 1993.
16. Degani A, Wiener EL. Cockpit checklists: concept, design, and use. Human Factors 1993; 35: 28-43.

17. Gross RL. Studies suggest methods for optimising checklist design and crew performance. Flight Safety Digest 1995; 14: 1-10.

18. Ferguson SA, Lamond N, Kandelaaris K, Jay SM, Dawson D. The impact of short, irregular sleep opportunities at sea on the alertness of marine pilots working extended hours. Chrono Int 2008; 25: 399-411. doi: 10.1080/07420520802106819.

19. Parker AW, Briggs J, Hubinger LM, Folkard S, Green S. The work practices of marine pilots: A Review. 1998. Available from http:// www.amsa.gov.au/Shipping_Safety/Coastal_Pilotage/Fatigue_study_on_Coastal_Pilots/The_work_practices_of_Marine_Pilots/ .

20. Caldwell JA, Caldwell JL, Schmid, RM. Alertness management strategies for operational contexts. Sleep Med Rev 2008; 12: 257-273. doi:10.1016/j.smrv.2008.01.002 .

21. McNamara R, Collins A, Matthews V. A review of research into fatigue in offshore shipping. Maritime review. Pacific Press, London 2000: 118-122. Retrieved from http://www.sirc.cf.ac.uk/uploads/ publications/Review\%20Fatigue\%200ffshore\%20Shipping.pdf.

22. MacLachlan M, Kavanagh B, Kay A. Maritime health: a review with suggestions for research. Int Marit Health. 2012; 63: 1-6.

23. Sauer J, Wastell DG, Hockey GRJ, Crawshaw CM, Ishak M, Downing $J C$. Effects of display design on performance in a simulated ship navigation environment. Ergonomics 2002; 45: 329-347.

24. Hockey GRJ, Healey A, Crawshaw M, Wastel, DG, Sauer J. Cognitive demands of collision avoidance in simulated ship control. Human Factors 2003; 45: 252-262. doi: 10.1518/hfes.45.2.252.27240.

25. Horizon Project. Fatigue at sea: Research report, 2011. Available from http://www.seahealth.dk/sites/default/files/Horizon\%20 research\%20-\%20Fatigue\%20at\%20Sea_0.pdf.

26. Salas E, Wilson KA, Burke S, Wightman DC. Does crew resource management training work? An update, and extension, and some critical needs. Human Factors 2006; 48: 392-412. doi: 10.1518/001872006777724444.

27. Helmreich RL, Merritt AC, Wilhelm JA. The evolution of crew resource management training in commercial aviation. Int J Avi Psych 1999; 9: 19-32.

28. Salas E, Burke CS, Bowers CA, Wilson KA. Team training in the skies: Does crew resource management (CRM) training work? Human Factors 2001; 43: 641-674.

29. Dwyer G. Literature review: fatigue management. NEO fire Fatigue Management Report: Department of Sustainability and Environment. Victorian Government, 2008. Available from http://www. dse.vic.gov.au. 